\title{
Qualidade microbiológica de leite UHT caprino: pesquisa de bactérias dos gêneros Staphylococcus, Bacillus e Clostridium
}

\author{
Microbiological quality of UHT goat milk: research of bacteria Staphylococcus, Bacillus and \\ Clostridium genus
}

\author{
Juliano Vittori $^{i^{*}}$ Rubén Pablo Schocken-Iturrino $^{\mathrm{I}}$ Maria Luiza Poiatti $^{\mathrm{I}}$ \\ Caroline Peters Pigatto ${ }^{\mathrm{II}}$ Tammy Priscila Chioda ${ }^{\mathrm{I}}$ César Augusto Martins Ribeiro ${ }^{\mathrm{II}}$ \\ Gisela Rojas Garcia' Adriana Valim Ferreira Ragazani ${ }^{\mathrm{I}}$
}

\section{RESUMO}

\begin{abstract}
Com o objetivo de avaliar a qualidade microbiológica do leite UHT caprino, 100 amostras provenientes das regiões Sul e Sudeste do país foram analisadas através do isolamento e da identificação de bactérias do gênero Staphylococcus sp., Bacillus sp. e Clostridium sp.. Com exceção do Clostridium sp., todos os gêneros estudados foram isolados. A presença de bactérias mesofílicas foi positiva em $21 \%$ das amostras. Bacillus sp. e Staphylococcus sp. foram isoladas em $32 \%$ e $36 \%$ das amostras analisadas respectivamente. As contagens de Staphylococcus sp. foram em média de $5,21 \times 10^{1}$ UFC $\mathrm{mL}^{-1}$, enquanto que para Bacillus sp. foi de $4,87 \times 10^{1} U F C \mathrm{~mL}^{-1}$. Os resultados encontrados sugerem que o processo térmico UHT utilizado nas amostras de leite não foi suficiente para destruir os microrganismos. Os resultados servem de alerta às autoridades responsáveis pela saúde pública para o risco potencial de determinadas bactérias produtoras de toxinas causarem intoxicação alimentar. Estes dados ressaltam a importância da criação de programas efetivos de controle $e$ prevenção destes agentes desde a obtenção do leite até seu beneficiamento.
\end{abstract}

Palavras-chave: bactéria, cabra, controle de qualidade, microbiologia

\section{ABSTRACT}

The aim of this study was to evaluate the microbiological quality of UHT (Ultra High Tempereture) goat milk. Microbiological analysis was used for detection and isolation of the genera Staphylococcus sp., Bacillus sp. and Clostridium sp. in one hundred of samples from different regions of the country. All genera mentioned, excepting Clostridium sp., have been found in the analyzed samples. The mesophilic bacteria were positive in $21 \%$ of samples. Bacillus sp. and Staphylococcus sp. were isolated in 32\% and 36\% of the analysed samples respectivelly. The mean of Staphylococcus sp. were of $5,21 \times 10^{1} \mathrm{CFU} \mathrm{mL}^{-1}$. Meanwhile for Bacillus sp. were
$4,87 \times 10^{1} \mathrm{CFU} \mathrm{mL}^{-1}$. The results suggest that thermal process UHT used in these samples was not enough to destroy the microorganisms. This information is important to warn Public Health authorities about the potential risks of these foodpoisoning microorganisms. Effective improvement of programs is necessary to control and prevent these agents therefore improving milk quality.

Key words: bacteria, goat, quality control, microbiology.

\section{INTRODUÇÃO}

Desde as primeiras civilizações, era comum o consumo de leite in natura, já que a única forma de preservação era através da produção de queijos e manteiga. Porém, sendo o leite um meio ótimo para desenvolvimento de microrganismos patogênicos e deteriorantes, ocorreu o aprimoramento de técnicas que possibilitaram garantir uma melhor conservação do produto, preservando a saúde do consumidor (POIATTI, 2005).

O tratamento térmico conhecido como UHT (ultra high temperature) ou UAT (ultra alta temperatura), usualmente denominado de leite "longa vida", consiste no aquecimento final entre $130 \mathrm{a} 150^{\circ} \mathrm{C}$, por 2 a 4 segundos, seguido de resfriamento a temperaturas inferiores a $32^{\circ} \mathrm{C}$ e envasado em embalagens assépticas (BRASIL, 1997). O produto obtido a partir do processamento UHT tem sido erroneamente denominado pela indústria de "leite esterilizado”, causando confusão ao consumidor, que

\footnotetext{
IDepartamento de Microbiologia, Universidade Estadual Paulista (UNESP), Via de acesso Prof. Paulo Donato Castellane, s/n, Zona Rural, 14870-970, Jaboticabal, SP, Brasil. *Autor para correspondência.

"Departamento Medicina Veterinária Preventiva, UNESP, Jaboticabal, SP, Brasil
} 
acredita tratar-se de um alimento “estéril”, por isso houve grande aceitação no mercado pelo maior prazo de validade e praticidade (POIATTI, 2005). Apesar de o tratamento UHT eliminar totalmente as formas vegetativas de microrganismos presentes no leite, formas esporuladas, altamente resistentes ao calor (highly heat resistant spores - HHRS), podem estar presentes no produto, devido às condições precárias de obtenção da matéria-prima (SCHOCKEN-ITURRINO et al., 1996). Nesse sentido, a grande preocupação está baseada nas bactérias esporuladas, cujos esporos são termo-resistentes ao tratamento térmico.

Mesmo não sendo precisamente divulgados, inúmeros estudos mostram que os principais fatores responsáveis por casos ou surtos de toxinfecção alimentar estão no manuseio incorreto dos alimentos desde a sua obtenção até a sua estocagem, incluindo a falta de higiene na sua obtenção ou no processamento e no tratamento térmico insuficiente ou incorreto (BAUTISTA et al., 1988; PASSOS e KUAYE, 1996; GELLI et al., 1999; LAGO, 2002).

SCHOCKEN-ITURRINO et al. (1996) pesquisaram os gêneros Bacillus sp. e Clostridium sp. no leite longa vida oriundo do comércio varejista na região de Ribeirão Preto - SP e obtiveram resultados positivos somente para o primeiro gênero, em 19 (59,37\%) do total de 32 amostras examinadas.

ANDRÉ et al. (1998), ao analisar 50 amostras de leite UHT adquiridas no varejo, em Goiânia-GO constataram $10 \%$ (5) das amostras positivas para Bacillus sp. (20\% da espécie Bacillus cereus e $80 \%$ não pertencem a este grupo). Nenhuma amostra apresentou positividade para o gênero Clostridium sp.. Dentro do gênero Bacillus sp., a espécie Bacillus cereus tem grande importância em saúde pública em virtude do potencial perigo devido à produção de toxinas durante o armazenamento do produto após envasado (POIATTI, 2005).

A importância de se conhecer a qualidade microbiológica de um dos alimentos mais importantes para a população, o leite, é fundamental para o ser humano. Por esta razão, este trabalho teve por objetivo avaliar a qualidade microbiológica do leite UHT caprino submetido a condições de armazenamento de mercado através do isolamento e da identificação por meio de testes bioquímicos paras as bactérias dos gêneros Staphylococcus sp., Bacillus sp. e Clostridium sp. Neste trabalho, foram analisadas amostras de duas marcas comerciais de leite UHT caprino disponíveis no mercado nacional.

\section{MATERIAL E MÉTODOS}

Foram colhidas 50 amostras de leite UHT, no período de agosto de 2005 a março de 2006, de um laticínio que processa leite UHT pelo sistema de injeção direta de vapor, localizado na cidade de Nova Friburgo - RJ e outras 50 amostras, adquiridas no comércio da região de Ribeirão Preto-SP, provenientes de um laticínio na cidade de Viamão - RS. As amostras oriundas da região de Ribeirão Preto eram adquiridas e imediatamente encaminhadas ao laboratório. As amostras colhidas no laticínio do Rio de Janeiro foram transportadas via correio e, imediatamente após a sua chegada, analisadas no Laboratório de Microbiologia da UNESP de Jaboticabal-SP. Antes de proceder às análises microbiológicas, as caixas de leite UHT foram incubadas a $37^{\circ} \mathrm{C}$ por sete dias, de acordo com as recomendações do Ministério da Agricultura, Abastecimento e da Reforma Agrária (BRASIL, 1996).

Para a análise das amostras de leite fluido, antes da retirada da unidade analítica, as embalagens foram devidamente descontaminadas, ou seja, inicialmente lavadas com água e detergente, secas com papel descartável, e limpas com etanol a 70\%. Após, foi realizada a homogeneização do conteúdo (invertendo-se 25 vezes) e abertas com instrumental esterilizado, em câmara de fluxo laminar. Foi retirada uma alíquota de $25 \mathrm{~mL}$ que depois foi transferida para um frasco contendo $225 \mathrm{~mL}$ de água peptonada $0,1 \%$ previamente esterilizada e homogeneizada por simples agitação, sendo posteriormente efetuadas as diluições seriadas até $10^{-3}$.

Para a contagem padrão de bactérias aeróbias mesófilas, $1,0 \mathrm{~mL}$ de cada diluição foi semeada em duplicata diretamente em placas de Petri esterilizadas, pelo método pour plate, contendo ágar para contagem padrão (PCA - Difco ${ }^{\circledR}$ ). As placas foram incubadas a $32-35^{\circ} \mathrm{C}$ por $24-48$ horas (BRASIL, 1993).

Para a contagem de Staphylococcus sp., 0,1mL das diluições foram semeadas, em duplicatas, na superfície de placas de Petri contendo ágar Baird Parker $\left(\right.$ Difco $^{\circledR}$ ), previamente esterilizado, e depois foram incubadas a $32-35^{\circ} \mathrm{C}$ por $24-48$ horas. As colônias características, negras, brilhantes, com ou sem halo, foram submetidas à verificação microscópica em esfregaços corados pelo método de Gram e posteriormente foi efetuado o teste da coagulase livre (APHA, 1992).

Para o isolamento do Bacillus sp., primeiramente as diluições foram submetidas a um aquecimento a $80^{\circ} \mathrm{C}$ por 10 minutos e resfriamento em água gelada (choque térmico), para ativação dos esporos e destruição das células vegetativas. Posteriormente, $0,1 \mathrm{~mL}$ de cada diluição foi semeado, 
em duplicata, em superfície das placas de Petri contendo ágar nutriente (NA - Difco $\left.{ }^{\circledR}\right)$, sendo estas então incubadas a $32-35^{\circ} \mathrm{C}$ por $24-48$ horas (BRASIL, 1993).

Para a contagem de Clostridium sp., as diluições foram submetidas a um choque térmico nas mesmas condições citadas anteriormente. Após esse procedimento, $0,1 \mathrm{~mL}$ das diluições foram semeadas, em duplicata, na superfície de placas de Petri contendo ágar BHI - infusão de cérebro e coração (BHI Difco ${ }^{\circledR}$ ). Estas placas foram incubadas em condições de anaerobiose utilizando jarras com o sistema Gás-Pak a temperatura de $35-37^{\circ} \mathrm{C}$ por 24-48horas (APHA, 1992).

A identificação foi feita pela detecção das bactérias Gram-positivas, com forma de bastonete, catalase negativa, anaeróbias e esporuladas, sendo estas repicadas em tubos de infusão de cérebro e coração (BHI-Difco), com tampas de rosca, incubados em anaerobiose a $35-37^{\circ} \mathrm{C}$, por 48 horas. Para confirmar a pureza das cepas, elas foram novamente repicadas para placas de SPS (Agar Sulfito Polimixina Sulfadiazina) e incubadas nas mesmas condições já citadas. As colônias puras foram submetidas à uma série de testes bioquímicos. Nestes testes foram avaliadas a presença de gelatinase, motilidade, fermentação de lactose, maltose, sacarose, bem como indol e salicina, usandose o meio de identificação para bactérias anaeróbias da API-bio Mérieux (APHA, 1992). Após as contagens, fez-se a análise descritiva dos dados segundo SAMPAIO (1998).

\section{RESULTADOS E DISCUSSÃO}

Na tabela 1, encontram-se os resultados das contagens (UFC mL $\mathrm{m}^{-1}$ ) de bactérias aeróbias mesófilas, Bacillus sp. e Staphylococcus sp. para as diferentes marcas de leite de cabra UHT estudadas. Pode -se notar os menores valores para as contagens de bactérias mesófilas nas amostras provenientes do laticínio do Rio Grande do Sul.

Para Bacillus sp., verifica-se que os leites provenientes do Rio de Janeiro apresentaram maior contaminação, sendo que $28 \%$ das amostras do laticínio gaúcho e 35\% do laticínio carioca foram positivas para a bactéria em questão (Tabela 1). As altas contagens talvez possam ser resultantes de procedimentos inadequados no momento da ordenha, assim como medidas higiênicas insatisfatórias. Este fato é alarmante visto que, mesmo a menor contaminação do laticínio gaúcho, pode ser capaz de veicular esporos termoresistentes capazes de produzir enterotoxinas

A literatura científica a respeito do leite caprino é escassa, sendo utilizados dados comparativos referentes às analises realizadas com leite bovino. Ao analisar quatro marcas de leite UHT bovino, obtidas no comércio de Ribeirão Preto, REZENDE (2000) encontrou bactérias do grupo Bacillus cereus em 41 (34\%) amostras do total de 120 analisadas, evidenciando qualidade microbiológica insatisfatória do leite UHT de bovinos. Dados similares foram relatados por LAGO (2002), ao analisar diferentes tipos de leite bovino (cru, em pó, pasteurizado e UHT), em que foi verificada a presença de Bacillus cereus em $13,3 \%$ das amostras de leite UHT. Este autor enfatiza a qualidade microbiológica do leite beneficiado, evidenciando que a matéria-prima deve conter menor carga de microrganismos possível para garantir um produto processado termicamente de boa qualidade.

VIDAL-MARTINS (2005), ao avaliar as características microbiológicas de diferentes marcas de leite UAT integral bovino, comercializado em São José do Rio Preto-SP, detectou a presença de Bacillus cereus em $20 \%$ (13) do total de amostras analisadas. Trabalhos no exterior, tais como o de BAHOUT (2000), verificaram presença de Bacillus cereus em 18 (29,2\%) das 60 amostras estudadas e sugerem que a presença dessa bactéria pode ser atribuída a fatores como qualidade do leite in natura e da água utilizada na higienização dos equipamentos, não-treinamento da mão-de-obra empregada, processamento inadequado do leite e contaminação pós-tratamento térmico.

Em todas amostras analisadas, não foi observada presença de Clostridium sp.. Observou-se que para Staphylococcus sp. as médias das contagens foram 3,19 x $10^{1} \mathrm{UFC} \mathrm{mL}^{-1}$ para as amostras do laticínio gaúcho e 7,22 x $10^{1} \mathrm{UFC} \mathrm{mL}^{-1}$ para os leites do laticínio carioca (Tabela 1 ).

Por sua vez, todas as amostras apresentaram resultados negativos para o teste de coagulase livre, evidenciando a ausência de Staphylococcus aureus. Apresentaram-se positivas para as contagens de Staphylococcus sp. 25\%(13) das amostras provenientes do laticínio gaúcho e 46\%(23) das amostras do laticínio carioca (Tabela 1). Determinadas cepas de Staphylococcus coagulase negativa (CSN) estão relacionadas com o casos de mastite severa em animais leiteiros, comprometendo a qualidade da matéria-prima destinada à industria láctea (JARP, 1991). Sabe-se que o gênero Staphylococcus sp. é bastante sensível às temperaturas de pasteurização (NADER FILHO, 1994), sendo assim acredita-se que os resultados sejam decorrentes da contaminação pós-processamento, através da deficiência na esterilização das embalagens, ou de uma recontaminação provocada pelos manipuladores. 
Tabela 1 - Contagens (Médias e desvios-padrão) e porcentagem de amostras positivas para bactérias aeróbias mesófilas, Staphylococcus sp. e Bacillus sp., em amostras de leite UHT caprino provenientes das regiões Sul e Sudeste do Brasil, colhidas no período de agosto de 2005 a março de 2006.

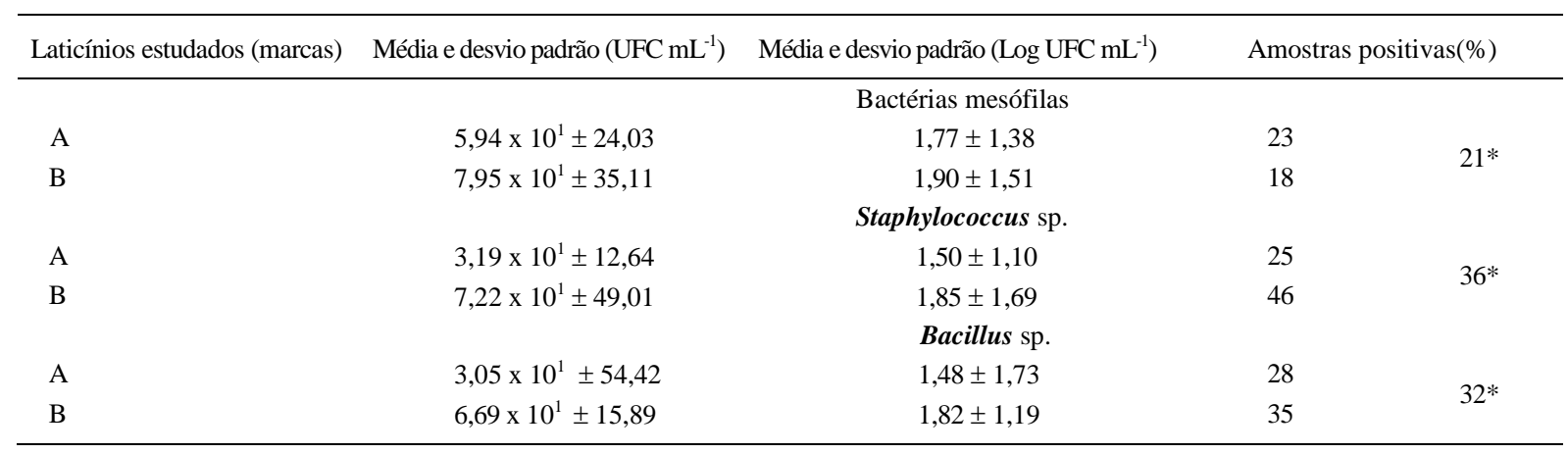

$\mathrm{A}=$ Amostras provenientes do laticínio localizado na cidade de Viamão - RS.

$\mathrm{B}=$ Amostras provenientes do laticínio localizado na cidade de Nova Friburgo - RJ.

* = Média do total de amostras analisadas.

\section{CONCLUSÃO}

A partir dos resultados obtidos, pôde-se demonstrar o nível de contaminação do leite UHT caprino. Além disso, pôde-se mostrar que muitas vezes o processo térmico não é suficiente para destruir tais agentes, evidenciando sua má qualidade microbiológica. Esses resultados servem de alerta às autoridades de saúde pública para o risco potencial de determinadas bactérias produtoras de toxinas causarem intoxicações alimentares, justificando, assim, a criação de programas efetivos de controle e prevenção destes agentes desde a obtenção do leite até seu beneficiamento.

\section{AGRADECIMENTO}

Agradecemos ao Conselho Nacional de Desenvolvimento Científico e Tecnológico (CNPq), pela concessão de bolsa de estudo.

\section{REFERÊNCIAS}

AMERICAN PUBLIC HEALTH ASSOCIATION. Committee on microbiological methods for foods. Compendium of methods for the microbiological examimation of foods. Washington: American Public Health Association, 1992. 701p.

ANDRÉ, M.C.D.P.B. et al. Isolamento e identificação de bactérias esporuladas mesófilas em leites UHT comercializados em Goiânia/GO. In: CONGRESSO LATINO AMERICANO DE MICROBIOLOGIA E HIGIENE DE ALIMENTOS, 5., - V COMBHAL, 1998, Águas deLindoia/SP. Anais... São Paulo: COMBHAL, 1998. v.1, p.119.

BAHOUT, A.A. Prevalence of Bacillus species in UHT milk. Assiut Veterinary Medical Journal, v.42, p.47-53, 2000.

BAUTISTA, L. et al. A quantitative study of enterotoxin production by sheep milk staphylococci. Applied and Environmental Microbiology, v.59, n.2, p.566-569, 1988.
BRASIL, Ministério da Agricultura, Abastecimento e Reforma Agrária. Portaria n. 146 de 07mar. 1996. Regulamentos técnicos de identidade e qualidade dos produtos lácteos. Diário Oficial da União, Brasília, 11 de mar. 1996. Seção 1. p.3978-3986.

BRASIL, Ministério da Agricultura, do Abastecimento e da Reforma Agrária. Métodos analíticos para o controle de produtos de origem animal e seus ingredientes - Métodos microbiológicos. Portaria no 101, Diário Oficial, 17 de Agosto de 1993.

BRASIL, Ministério da Agricultura. Portaria no 370 de 4 de setembro de 1997. Regulamento técnico de identidade e qualidade do leite UAT (UHT). Brasília. 9p.

GELLI, D.S. et al. Surtos de enfermidades transmitidas por alimentos (ETAs) investigados pelos laboratórios de saúde pública do Estado de São Paulo, no período de 1994 a 1998. In: Congresso Brasileiro de Microbiologia, 20., 1998, Salvador (BA). Anais... Salvador: CBM, 1999. p.126

JARP, J. Classification of coagulase-negative Staphylococcus isolated from bovine clinical and subclinical mastitid. Veterinary Microbiology, v.27, p.151-158, 1991.

LAGO, N.C.M.R. Bactérias do grupo do Bacillus cereus em leite e estudo enterotoxigênico das cepas isoladas. 2002. 70f. Tese (Doutorado em Medicina Veterinária Preventiva) Faculdade de Ciências Agrárias e Veterinárias, Universidade Estadual Paulista, Jaboticabal.

NADER FILHO, A. Eficiência do processo de pasteurização lenta do leite previamente envasado. Arquivo Brasileiro de Medicina Veterinária e Zootecnia, v.46, n.6, p.729-36, 1994.

PASSOS, M.H.C.R.; KUAYE, A.Y. Relato de surtos de intoxicação alimentar provocada por consumo de bolo contaminado por Staphylococcus aureus - importância da higiene dos manipuladores e condições de conservação do alimento na prevenção da doença. Revista do Instituto Adolfo Lutz, v.56, n.1, p.71-76, 1996. 
POIATTI, M.L. Características microbiológicas de diferentes leites caprinos. 2005. 62f. Tese (Doutorado em Zootecnia) - Faculdade de Ciências Agrárias e Veterinárias, Universidade Estadual Paulista, Jaboticabal.

REZENDE, N.C.M et al. Ocorrência de bactérias do grupo Bacillus cereus em leite UHT integral (Ultra-HighTemperature). Revista Brasileira de Ciência Veterinária, Niterói v.7, n.3, p.162-166, 2000.

SAMPAIO, I.B.M. Estatística descritiva básica. In: Estatística aplicada à experimentação animal. Belo
Horizonte: Fundação de Ensino e Pesquisa em Medicina Veterinária e Zootecnia, 1998. p.14-19

SCHOCKEN-ITURRINO, R.P. et al. Ocorrência de bactérias esporuladas dos gêneros Bacillus e Clostridium em amostras de leite longa vida. Higiene Alimentar, v.10, n.42, p.25-27, 1996.

VIDAL-MARTINS, A.M.C. et al. Mesophilic heterotrophic microorganisms and spore forming bacteria from Bacillus cereus group in ultra high temperature milk. Arquivo Brasileiro de Medicina Veterinária e Zootecnia, v.57, n.3, p.396-400, 2005. 